Pinto, MVB, Torres, FE, Zanuncio, AS, Teodoro, PE, Mendonça, GG \& Capristo, DP. (2020). Selection of soybean cultivars in the closedpantanal eco-toon region. Research, Society and Development, 9(7): 1-12, e434973823.

\title{
Seleção de cultivares de soja na região do ecótono cerrado-pantanal
}

Selection of soybean cultivars in the closed-pantanal eco-toon region

Selección de cultivares de soja en la región del ecotón cerrado-pantanal

Recebido: 21/04/2020 | Revisado: 28/04/2020 | Aceito: 12/05/2020 | Publicado: 21/05/2020

Marcos Vinícius Barros Pinto

ORCID: https://orcid.org/0000-0002-1238-0202

Universidade Estadual de Mato Grosso do Sul- Brasil

E-mail: mbarrosp31@gmail.com

Francisco Eduardo Torres

ORCID: https://orcid.org/0000-0002-6114-0096

Universidade Estadual de Mato Grosso do Sul- Brasil

E-mail: feduardo@uems.br

Angelita dos Santos Zanuncio

ORCID: https://orcid.org/ 0000-0002-7191-8498

Universidade Estadual de Mato Grosso do Sul- Brasil

E-mail: angelitazanuncio@gmail.com

Paulo Eduardo Teodoro

ORCID: https://orcid.org/0000-0002-8236-542X

Universidade Federal de Mato Grosso do Sul- Brasil

E-mail: eduteodoro@hotmail.com

Gabriele Gonçalves de Mendonça

ORCID: https://orcid.org/0000-0001-5659-4109

Universidade Estadual de Mato Grosso do Sul- Brasil

E-mail: gabriele.goncalves@ outlook.com

Denise Prevedel Capristo

ORCID: https://orcid.org/0000-0001-8906-3726

Universidade Estadual de Mato Grosso do Sul- Brasil

E-mail: denise_prevedel@hotmail.com 


\section{Resumo}

O objetivo deste trabalho foi avaliar o desempenho de dezesseis cultivares de soja e indicar aqueles com melhor adaptação para o cultivo na região de Aquidauana, MS. O trabalho foi realizado na área experimental da Universidade Estadual de Mato Grosso do Sul, Unidade de Aquidauana, no ano agrícola 2014/2015, em sistema plantio convencional. O delineamento experimental utilizado foi o inteiramente casualizado, com 16 tratamentos (RR: 97R21, 97R71, 97R73, 97Y07, AS3610, AS3730, AS3797, B4184, B4377, CD238, MOSOY6410, P98Y11, POTÊNCIA, SYN1163, SYN13671 e SYN9070) e 4 repetições. As parcelas consistiram de sete linhas com $5 \mathrm{~m}$ de comprimento, com espaçamento de 0,45 m entre linhas e densidade de 15 plantas por metro. Foram avaliados os caracteres agronômicos altura de planta na maturação, altura de inserção de primeira vagem, número de ramificações, número de vagens por planta, número de grãos por vagens, massa de cem grãos e produtividade de grãos. Após a coleta dos dados foi verificado o ajuste dos erros pelo teste de Liliefors e a homogeneidade das variâncias pelo teste de Bartlett, e os dados foram submetidos a analise de variância e ao agrupamento de médias pelo teste de Skott-Knott á 5\% de probabilidade. Conclui-se que a cultivar B4377 obteve o melhor desempenho analisando as variáveis AP, AIV, NR e NVP em conjunto. As cultivares que obtiveram melhor desempenho analisando as variáveis NGV, MCG e PROD em conjunto foram AS3730 e P98Y11. Altura de planta NVP e MCG não influenciaram na melhor produtividade de grãos. Considerando a produtividade de grãos, todos os materiais avaliados podem ser recomendados para a região.

Palavras-chave: Adaptabilidade; Cultivares; Massa de cem grãos.

\section{Abstract}

The objective of this work was to evaluate the performance of sixteen soybean cultivars and to indicate those with the best adaptation to the cultivation in the region of Aquidauana, MS. The work was carried out in the experimental area of the State University of Mato Grosso do Sul, Unit of Aquidauana, in the agricultural year 2014/2015, in conventional planting system. The experimental design was a completely randomized design with 16 treatments (RR: 97R21，97R71，97R73，97Y07，AS3610，AS3730，AS3797，B4184，B4377，CD238, MOSOY6410, P98Y11, POWER, SYN1163, SYN13671 and SYN9070) . The plots consisted of seven lines with $5 \mathrm{~m}$ of length, with spacing of $0.45 \mathrm{~m}$ between rows and density of 15 plants per meter. The agronomic characteristics of plant height at maturity, height of first pod insertion, number of branches, number of pods per plant, number of grains per pods, mass of one hundred grains and grain yield were evaluated. After data collection, the Liliefors test was 
adjusted for error and the variance homogeneity was verified by the Bartlett test, and the data were submitted to analysis of variance and the grouping of means by the Skott-Knott test at $5 \%$ probability. It was concluded that the cultivar B4377 obtained the best performance by analyzing the variables AP, AIV, NR and NVP together. The cultivars that obtained the best performance by analyzing the variables NGV, MCG and PROD together were AS3730 and P98Y11. Plant height NVP and MCG did not influence the best grain yield. Considering grain yield, all evaluated materials may be recommended for the region.

Keywords: Adaptability; Cultivar; Mass of one hundred grains.

\section{Resumen}

El objetivo de este trabajo fue evaluar el desempeño de dieciséis cultivares de soya e indicar aquellos con una mejor adaptación para el cultivo en la región de Aquidauana, MS. El trabajo se llevó a cabo en el área experimental de la Universidad Estatal de Mato Grosso do Sul, Unidad Aquidauana, en el año agrícola 2014/2015, bajo un sistema de plantación convencional. El diseño experimental utilizado fue completamente al azar, con 16 tratamientos (RR: 97R21, 97R71, 97R73, 97Y07, AS3610, AS3730, AS3797, B4184, B4377, CD238, MOSOY6410, P98Y11, POWER, SYN1163, SYN13671 y SYN9070) y 4 repeticiones . Las parcelas consistieron en siete líneas de $5 \mathrm{~m}$ de largo, con un espacio de 0,45 m entre líneas y una densidad de 15 plantas por metro. Rasgos agronómicos: se evaluaron la altura de la planta en la maduración, la altura de la inserción de la primera vaina, la cantidad de ramas, la cantidad de vainas por planta, la cantidad de granos por vaina, la masa de cien granos y el rendimiento de grano. Después de la recopilación de datos, el ajuste de errores se verificó mediante la prueba de Liliefors y la homogeneidad de las variaciones mediante la prueba de Bartlett, y los datos se sometieron a análisis de varianza y la agrupación de medias mediante la prueba de Skott-Knott con un 5\% de probabilidad. . Se concluyó que el cultivar B4377 obtuvo el mejor rendimiento al analizar las variables AP, AIV, NR y NVP juntas. Los cultivares que obtuvieron el mejor rendimiento analizando las variables NGV, MCG y PROD juntos fueron AS3730 y P98Y11. La altura de la planta NVP y MCG no influyeron en el mejor rendimiento de grano. Considerando el rendimiento de grano, todos los materiales evaluados pueden ser recomendados para la región.

Palabras clave: Adaptabilidad; Cultivares; Cien granos de masa. 


\section{Introdução}

A soja (Glycine max (L.) Merrill) é considerada uma fonte de proteína completa, isto é, contém quantidades significativas da maioria dos aminoácidos essenciais que devem ser providos ao corpo humano por fontes externas, devido de sua inabilidade para sintetizá-los.

No contexto mundial, o Brasil possui significativas participações na oferta e na demanda de produtos do complexo agroindustrial da soja, o qual vem desempenhando papel fundamental para o desenvolvimento de várias regiões do país (Embrapa, 2004).

O Brasil é o maior produtor de soja do mundo, ficando em segundo lugar Estados Unidos, sendo considerado o país com a maior média de produtividade e o maior exportador mundial de grão e farelo. Na safra 2019/2020, a produção brasileira chegou a 122,4 milhões de toneladas, com uma área plantada de 33.8 milhões de hectares, atingindo uma produtividade média de $3.362 \mathrm{~kg}$ ha- 1 .

O Paraná alcançou 3.721 kg ha-1, a melhor produtividade de soja do país nessa safra. Mato Grosso é o maior produtor, com 30,5 milhões de toneladas de grãos, em 9,3 milhões de hectares, com produtividade média de $3.273 \mathrm{~kg}$ ha-1 (Conab, 2020).

A maneira de se prevenir contra possíveis adversidades climáticas e obter ganhos em produtividade é a obtenção de materiais adaptados às condições edafoclimáticas de cada região e a utilização de tecnologias de materiais genéticos de alto potencial produtivo (Torres et al., 2014).

A região do ecótono cerrado pantanal, anteriormente utilizada quase que exclusivamente para a atividade da pecuária de corte, vem passando por uma transformação no seu modelo econômico com a introdução da cultura da soja, principalmente no sistema de integração lavoura pecuária.

Pesquisas voltadas para a identificação e seleção de cultivares de soja adaptadas as condições edafoclimáticas locais, que diferem das demais regiões produtoras do estado, são importantes para a viabilidade técnica e econômica.

Nesse contexto, o objetivo deste trabalho foi avaliar o desempenho de cultivares de soja no município de Aquidauana, a fim de se identificar aquelas que possam ser recomendadas na região. 


\section{Metodologia}

Uma pesquisa busca trazer novos saberes à sociedade como preconiza Pereira et al. (2018). Quando as pesquisas são em campo há uma dificuldade maior em relação as pesquisas laboratoriais cujas variáveis podem ser controladas. O presente experimento de natureza quantitativa com pequeno viés qualitativo foi conduzido na safra 2014/2015 no setor de Fitotecnia, à campo, na Universidade Estadual de Mato Grosso do Sul - Unidade Universitária de Aquidauana (UEMS/UUA), no município de Aquidauana-MS $\left(20^{\circ} 27^{\prime} \mathrm{S}\right.$ e $55^{\circ} 40^{\prime} \mathrm{W}$, com uma altitude média de $170 \mathrm{~m}$ ). O solo da área foi classificado como Argissolo VermelhoAmarelo distrófico de textura arenosa, com as seguintes características na camada de 0 - 0,20 m: $\mathrm{pH}\left(\mathrm{H}_{2} \mathrm{O}\right)=6,2 ; \mathrm{Al}$ trocável $\left(\mathrm{cmol}^{\mathrm{c}} \mathrm{dm}-3\right)=0,0 ; \mathrm{Ca}+\mathrm{Mg}\left(\mathrm{cmol}^{\mathrm{c}} \mathrm{dm}^{-3}\right)=4,31 ; \mathrm{P}\left(\mathrm{mg} \mathrm{dm}^{-3}\right)$ $=41,3 ; \mathrm{K}\left(\mathrm{cmol}^{\mathrm{c}} \mathrm{dm}^{-3}\right)=0,2 ;$ Matéria orgânica $\left(\mathrm{g} \mathrm{dm}^{-3}\right)=19,74 ; \mathrm{V}(\%)=45 ; \mathrm{m}(\%)=0,0$; Soma de bases $\left(\mathrm{cmol}^{\mathrm{c}} \mathrm{dm}^{-3}\right)=2,3 ; \operatorname{CTC}\left(\mathrm{cmol}^{\mathrm{c}} \mathrm{dm}^{-3}\right)=5,1$. O clima da região, segundo a classificação de Köppen-Geiger, é do tipo Aw (Tropical de Savana) com precipitação acumulada no período experimental de $464 \mathrm{~mm}$ e temperaturas máximas e mínimas médias de 37,7 e $16,9^{\circ} \mathrm{C}$, respectivamente.

O delineamento experimental utilizado foi o de blocos casualizados, com dezesseis tratamentos e quatro repetições. Os tratamentos foram constituídos por 16 cultivares de soja RR: 97R21, 97R71, 97R73, 97Y07, AS3610, AS3730, AS3797, B4184, B4377, CD238, MOSOY6410, P98Y11, POTÊNCIA, SYN1163, SYN13671 e SYN9070. As parcelas consistiram de sete linhas com $5 \mathrm{~m}$ de comprimento, com espaçamento de $0,45 \mathrm{~m}$ entre linhas e densidade de 15 plantas por metro.

Na preparação da área experimental foi realizado o preparo do solo, constou de uma gradagem pesada e duas gradagens niveladoras após as quais se realizou a abertura mecânica dos sulcos. Não foi realizada adubação de base tendo em vista a fertilidade do solo. Foi realizada dessecação com o herbicida Gliphosate na dose de $6 \mathrm{~L} \mathrm{ha}^{-1}$, empregando-se na aplicação pulverizador de barras equipado com bico do tipo cone. As sementes foram tratadas com fungicida (piraclotrobina + metil tiofanato) e inseticida (fipronil), na dose de $200 \mathrm{~mL}$ do produto comercial para cada $100 \mathrm{~kg}$ de sementes afim de se garantir proteção contra o ataque de pragas e doenças na fase inicial de desenvolvimento da cultura. Para a fixação biológica de nitrogênio (FBN), as sementes foram inoculadas com bactérias do gênero Bradyrhizobium, sendo utilizada a dose de $200 \mathrm{~mL}$ de inoculante líquido concentrado para cada $100 \mathrm{~kg}$ de sementes. 
O controle de pragas foi realizado com a aplicação dos inseticidas metomil, na dose de $600 \mathrm{~mL} \mathrm{ha}^{-1}$ do produto comercial, e tametoxam + lambda-cialotrina na dose de $200 \mathrm{~mL} \mathrm{ha}^{-1}$, sendo aplicados com pulverizador costal de bico cônico.

Para o controle de plantas infestantes foi utilizado o herbicida glifosato na dose de $6 \mathrm{~L}$ $\mathrm{ha}^{-1} \mathrm{e}$, posteriormente, capina manual. Para o controle de doenças foi realizado a aplicação de um fungicida trifloxistrobina + protioconazol, na dose de $400 \mathrm{~mL} \mathrm{ha}^{-1}$ do produto comercial, e na dessecação foi realizado a aplicação do herbicida paraquat, na dose de $2 \mathrm{~L} \mathrm{ha}^{-1}$.

Foram avaliados os seguintes caracteres agronômicos: altura das plantas na maturação (AP), altura da inserção da primeira vagem (AIV), número de ramificações (NR), número de vagens por planta (NVP), número de grãos por vagem (NGV), massa de cem grãos (MCG) e produtividade de grãos (PROD). Para as avaliações foram colhidas, aleatoriamente, 10 plantas de cada parcela, sendo as variáveis AP e AIV mensuradas em $\mathrm{cm}$ com auxílio de fita milimetrada. Nestas plantas foram contados o NR, NV e NGV. Para determinação da PROD foram colhidas duas fileiras centrais de cada parcela, sendo os grãos pesados, corrigidos para $13 \%$ de umidade e os valores extrapolados para $\mathrm{kg} \mathrm{ha}^{-1}$. Para obtenção da MCG, em g, cinco amostras foram retiradas deste montante, pesadas e corrigidas para $13 \%$ de umidade.

Após verificar o ajuste dos erros a distribuição normal pelo teste de Lilliefors e a homogeneidade das variâncias pelo teste de Bartlett, os dados foram submetidos a análise de variância e ao agrupamento de médias pelo teste de Skott-Knott a 5\% de probabilidade. Todas as análises foram feitas com software Genes (Cruz, 2013).

\section{Resultados e Discussão}

De acordo com a análise de variância houve diferenças significativas, entre as cultivares nas variáveis AP, AIV, NVP, NGV, MCG e PROD (Tabela 1). Torres et al. (2014, 2015) também observaram variabilidade genética entre cultivares de soja produzidas na mesma região desse experimento.

Quando falamos de seleção de genótipos com alto desempenho agronômico, caracteres agronômicos como altura de planta, altura de inserção da primeira vagem, massa de cem grãos e produtividade são essenciais (Neves, 2011; Leite, 2016). 
Tabela 1. Resumo da análise de variância para as variáveis altura de plantas (AP), altura de inserção de vagens (AIV), número de ramificações (NR), número de vagens (NV), número de grãos por vagens (NGV), massa de cem grãos (MCG) e produtividade de grãos (PROD) avaliadas em 16 cultivares de soja cultivadas no ecótono Cerrado/Pantanal.

\begin{tabular}{lllllllll}
\hline FV & GL & AP & AIV & NR & NVP & NGV & MCG & PROD \\
\hline Bloco & 3 & $142,32^{\text {ns }}$ & $32,42^{*}$ & $2,33^{\text {ns }}$ & $527,78^{*}$ & $0,26^{\text {ns }}$ & $2,55^{*}$ & $152.943 .11^{\text {ns }}$ \\
Cultivares & 15 & $497,03^{*}$ & $14,20^{*}$ & $1,97^{\text {ns }}$ & $491,05^{*}$ & $0,20^{*}$ & $7,61^{*}$ & $1.239 .057,89^{*}$ \\
Erro & 45 & 82,41 & 5,28 & 1,24 & 115,66 & 0,11 & 0,70 & $317.032,35$ \\
\hline CV $(\%)$ & --- & 13,03 & 19,02 & 22,23 & 17,34 & 13,75 & 5,26 & 14,97 \\
\hline
\end{tabular}

${ }^{\text {ns }}$ e *: não significativo e significativo a $5 \%$ de probabilidade pelo teste $\mathrm{F}$, respectivamente. FV: fontes de variação; CV: coeficiente de variação; GL: graus de liberdade. Fonte: Elaborada pelo autor.

As cultivares que obtiveram as maiores médias para altura de planta (AP) foram 97R21 (73,3cm), 97R73 (89,4cm), AS3730 (76,3 cm), B4184 $(86,7 \mathrm{~cm})$, B4377 $(82,1 \mathrm{~cm})$, SYN9070 (78,7cm) (Tabela 2). Segundo Bonetti (1983) e Francischini et al. (2000), a altura ideal de planta varia de 60 a $120 \mathrm{~cm}$, e nesse experimento a maioria dos genótipos avaliados obtiveram médias superiores de $60 \mathrm{~cm}$, sendo somente as cultivares 97R71, AS3797 e P98Y11 que obtiveram médias inferiores.

A recomendação para altura de planta visa a diminuição das perdas durante o processo de colheita, pois o acamamento vai dificultar a retirada dessas plantas, além de influenciar também na incidência das plantas daninhas, diminuindo a produção (Neves, 2011; Bossolani et al., 2015).

Tabela 2. Valores médios para as variáveis altura de plantas (AP), altura de inserção de vagens (AIV), número de ramificações (NR) e número de vagens por planta (NVP), avaliadas em 16 cultivares de soja cultivadas no ecótono Cerrado/Pantanal.

\begin{tabular}{|c|c|c|c|c|c|c|c|c|}
\hline \multirow{2}{*}{$\frac{\text { Cultivar }}{97 \mathrm{R} 21}$} & \multicolumn{2}{|c|}{$\mathrm{AP}(\mathbf{c m})$} & \multicolumn{2}{|c|}{ AIV (cm) } & \multicolumn{2}{|c|}{ NR } & \multicolumn{2}{|c|}{ NVP } \\
\hline & 73,3 & $\mathrm{a}$ & 13,2 & $\mathrm{a}$ & 5,0 & $\bar{a}$ & 60,7 & $\mathrm{~b}$ \\
\hline $97 \mathrm{R} 71$ & 48,2 & $\mathrm{c}$ & 11,6 & $\mathrm{~b}$ & 5,1 & a & 56,5 & $\mathrm{~b}$ \\
\hline $97 R 73$ & 89,4 & $\mathrm{a}$ & 14,2 & $\mathrm{a}$ & 4,8 & $\mathrm{a}$ & 54,8 & $\mathrm{~b}$ \\
\hline 97Y07 & 69,3 & $\mathrm{~b}$ & 11,5 & $\mathrm{~b}$ & 4,6 & $\mathrm{a}$ & 85,2 & $\mathrm{a}$ \\
\hline AS3610 & 66,3 & $\mathrm{~b}$ & 9,9 & $\mathrm{~b}$ & 5,4 & $\mathrm{a}$ & 77,6 & $\mathrm{a}$ \\
\hline AS3730 & 76,3 & $\mathrm{a}$ & 12,4 & $\mathrm{a}$ & 3,7 & $\mathrm{a}$ & 61,9 & $\mathrm{~b}$ \\
\hline AS3797 & 54,5 & $\mathrm{c}$ & 13,2 & $\mathrm{a}$ & 5,4 & $\mathrm{a}$ & 74,6 & $\mathrm{a}$ \\
\hline B4184 & 86,7 & $\mathrm{a}$ & 14,6 & $\mathrm{a}$ & 4,6 & $\mathrm{a}$ & 55,1 & b \\
\hline B4377 & 82,1 & $\mathrm{a}$ & 15,6 & $\mathrm{a}$ & 5,7 & $\mathrm{a}$ & 67,5 & $\mathrm{a}$ \\
\hline COODETEC2728 & 63,4 & $\mathrm{~b}$ & 9,4 & $\mathrm{~b}$ & 6,6 & $\mathrm{a}$ & 68,8 & $\mathrm{a}$ \\
\hline MOSOY6410 & 68,0 & $\mathrm{~b}$ & 11,1 & $\mathrm{~b}$ & 4,6 & $\mathrm{a}$ & 50,1 & $\mathrm{~b}$ \\
\hline P98Y11 & 59,0 & $\mathrm{c}$ & 13,1 & $\mathrm{a}$ & 5,6 & $\mathrm{a}$ & 49,8 & $\mathrm{~b}$ \\
\hline POTENCIA & 65,3 & $\mathrm{~b}$ & 12,6 & $\mathrm{a}$ & 4,3 & $\mathrm{a}$ & 56,0 & $\mathrm{~b}$ \\
\hline SYN1163RR & 68,3 & $\mathrm{~b}$ & 8,8 & $\mathrm{~b}$ & 5,9 & $\mathrm{a}$ & 59,7 & $\mathrm{~b}$ \\
\hline SYN13671 & 66,8 & $\mathrm{~b}$ & 10,9 & $\mathrm{~b}$ & 4,6 & $\mathrm{a}$ & 44,7 & $\mathrm{~b}$ \\
\hline SYN9070 & 78,7 & $\mathrm{a}$ & 11,7 & $\mathrm{~b}$ & 5,0 & $\mathrm{a}$ & 69,8 & $\mathrm{a}$ \\
\hline Média & 69,7 & & 12,1 & & 5,0 & & 62,0 & \\
\hline
\end{tabular}

Médias seguidas por letras iguais na mesma coluna não diferem entre si pelo teste de Skott-Knott a 5\% de probabilidade. Fonte: Elaborado pelo autor.

Na variável altura de inserção da primeira vagem (AIV) as cultivares que obtiveram as maiores médias foram: 97R21 (13,2cm), 97R23 (14,2cm), AS3730 (12,4cm), AS3797 
Existem várias recomendações para esta variável na literatura, Bonetti (1983) e Francichini et al. (2000) descrevem que a AIV ideal é de $15 \mathrm{~cm}$, e Queiroz et al. (1981) relata que esta deve ser de 10 a $13 \mathrm{~cm}$. Assim, podemos dizer que apenas as cultivares AS3610 $(9,9)$, COODETEC2 $(9,4)$ e SYN1163RR $(8,8)$ não se enquadra nas recomendações.

Apesar de AIV ser uma característica de cada cultivar, os fatores ambientais e as práticas culturais que podem influenciar na altura de planta, interferem também na inserção da primeira vagem (Torres et al., 2014).

Não houve diferença significativa entre as cultivares no variável número de ramificações (NR). O NR está relacionado com a competição por fatores de crescimento como luz, água e nutrientes que ocorre nas linhas de plantio, isso vai diminuir a disponibilidade de fotoassimilados para as plantas, determinando maior ou menor número de ramificações (Torres et al., 2015; Costa, 2013).

Nos nós das plantas se desenvolvem as gemas reprodutivas que darão origem as vagens, assim, quanto maior o NR, maior será o número de vagens por planta (NVP) (Costa, 2013). Neste experimento as cultivares que obtiveram as maiores médias para esta variável foram 97 Y07 (85,2), AS3610 (77,6), AS3797 (74,6), B4377 (67,5), COODETEC2 $(68,8)$, SYN9070 (69,8). Resultado semelhante foram encontrados por Torres et al. $(2014,2015)$ onde encontraram diferenças significativas para (NVP) em cultivares de soja.

Todas essas variáveis (AP, AIV, NR e NVP) são características que podem ser influenciadas pela época de semeadura, pelo espaçamento e pela população de plantas. Segundo Neves (2011), maiores populações estimulam o crescimento das plantas, resultando em aumento da altura e, consequentemente, maior inserção da primeira vagem. Em semeaduras mais adensadas pode ocorrer uma diminuição no número de ramificações e no número de vagens, diminuindo a produção de grãos (Torres et al., 2014).

Considerando apenas AP, AIV, NR e NVP, podemos afirmar que a cultivar B4377 foi a que teve o melhor resultado, com valores de $82,1 \mathrm{~cm}$ de altura de planta, $15,6 \mathrm{~cm}$ de altura de inserção da primeira vagem, 5,7 números de ramificações e 67,5 números de vagens por planta.

As maiores médias de número de grãos por vagem (NGV) podem ser observadas nas cultivares 97R73 (2,7), AS3610 (2,6), AS3730 (2,8), AS3797 (2,6) B4184 (2,6), CODETEC2 $(2,6)$ E P98Y11 $(2,8)$ (Tabela 3). Resultados superiores aos encontrados por Castoldi et al. (2009), onde avaliando o desempenho de genótipos de soja, observaram uma média de 2,1 grãos por vagem. 
Apesar de ter ocorrido uma diferença significativa entre as cultivares quanto ao NGV, segundo Neves (2011) esta característica é tipicamente genética de cada cultivar, não sendo muito influenciada por fatores do meio ambiente, como é o caso do número de vagens por planta. Sendo a maioria das cultivares de soja selecionadas para formar três óvulos por vagem (Costa, 2013).

Para a variável massa de cem grãos (MCG) as cultivares que obtiveram as maiores médias foi respectivamente: 97R73 (15,8g), AS3610 (16,1g), AS3730 (16,8g), AS3797 $(14,0 \mathrm{~g})$, B4184 (13,6g), CODETEC2 (15,6g) e P98Y11 (16,7g). Divergindo dos resultados encontrados por Torres et al. (2014), onde não observaram diferenças significativas entre as cultivares de soja produzidas na mesma região. Porém, a média final foi inferior a observada por eles, de 20,58 g, sendo neste experimento a média foi de $16 \mathrm{~g}$. Apesar de a MCG também ser um caractere que não sofre influência do meio ambiente, é fundamental para estimar a produtividade de grãos, tornando-se importante na identificação de qual genótipo com auto rendimento melhor se adaptou à região (Torres et al., 2014).

Tabela 3. Valores médios para as variáveis número de grãos por vagens (NGV), massa de cem grãos (MCG) e produtividade de grãos (PROD) avaliadas em 16 cultivares de soja cultivadas no ecótono Cerrado/Pantanal.

\begin{tabular}{lccc}
\hline Cultivar & NGV & MCG & PROD \\
\hline 97R21 & $2,3 \mathrm{~b}$ & $16,8 \mathrm{a}$ & $3.299,09 \mathrm{~b}$ \\
97R71 & $2,1 \mathrm{~b}$ & $16,4 \mathrm{~b}$ & $3.982,94 \mathrm{a}$ \\
97R73 & $2,7 \mathrm{a}$ & $15,8 \mathrm{~b}$ & $4.143,24 \mathrm{a}$ \\
97Y07 & $2,3 \mathrm{~b}$ & $16,0 \mathrm{~b}$ & $3.795,61 \mathrm{~b}$ \\
AS3610 & $2,6 \mathrm{a}$ & $16,1 \mathrm{~b}$ & $3.988,51 \mathrm{a}$ \\
AS3730 & $2,8 \mathrm{a}$ & $16,8 \mathrm{a}$ & $4.135,91 \mathrm{a}$ \\
AS3797 & $2,6 \mathrm{a}$ & $14,0 \mathrm{~b}$ & $4.298,81 \mathrm{a}$ \\
B4184 & $2,6 \mathrm{a}$ & $13,6 \mathrm{~b}$ & $3.482,89 \mathrm{~b}$ \\
B4377 & $2,3 \mathrm{~b}$ & $17,0 \mathrm{a}$ & $3.614,51 \mathrm{~b}$ \\
COODETEC2728 & $2,6 \mathrm{a}$ & $15,6 \mathrm{~b}$ & $3.672,60 \mathrm{~b}$ \\
MOSOY6410 & $2,3 \mathrm{~b}$ & $16,8 \mathrm{a}$ & $3.341,54 \mathrm{~b}$ \\
P98Y11 & $2,8 \mathrm{a}$ & $16,7 \mathrm{a}$ & $4.161,65 \mathrm{a}$ \\
POTENCIA & $2,3 \mathrm{~b}$ & $15,1 \mathrm{~b}$ & $3.761,12 \mathrm{~b}$ \\
SYN1163RR & $2,1 \mathrm{~b}$ & $17,2 \mathrm{a}$ & $3.034,25 \mathrm{~b}$ \\
SYN13671 & $2,4 \mathrm{~b}$ & $18,8 \mathrm{a}$ & $3.150,69 \mathrm{~b}$ \\
SYN9070 & $2,2 \mathrm{~b}$ & $13,9 \mathrm{~b}$ & $4.235,41 \mathrm{a}$ \\
\hline Média & 2,4 & 16,0 & 3.761 \\
\hline
\end{tabular}

Médias seguidas por letras iguais na mesma coluna não diferem entre si pelo teste de Skott-Knott a 5\% de probabilidade. Fonte: Elaborada pelo autor. 
Quanto a produtividade de grãos, as cultivares que obtiveram as maiores médias (kg ha-1) foram 97R71 (3.982,94), 97R73 (4.143,24), AS3610 (3.988,51), AS 3730 (4.135,91), AS3797 (4.298,81), P98Y11 $(4.161,65)$ e SYN9070 $(4.235,41)$, superiores a produtividade média fornecida pela Conab para o estado de Mato Grosso do Sul, que é $3.120 \mathrm{~kg} \mathrm{ha}^{-1}$ (CONAB, 2015). Somente a cultivar SYN1163RR obteve média abaixo desse valor, 3.034,25 $\mathrm{kg} \mathrm{ha}^{-1}$, respectivamente.

Analisando as variáveis NGV, MCG e PROD em conjunto, verificamos que as cultivares com melhor desempenho foram AS3730 e P98Y11. Podendo assim inferir que tais materiais se adaptam muito bem às condições edafoclimáticas da Região.

Considerando as cultivares que produziram acima de $4.000 \mathrm{~kg}$ há $^{-1}$, não há como afirmar que o parâmetro altura de planta influenciou na produtividade visto que o mesmo variou de 54,5 a 89,4 cm. O mesmo ocorreu para NVP e MCG que por sua vez nem sempre apresentaram os maiores valores.

\section{Conclusão}

A cultura da soja se adapta a diferentes regiões, dependendo de cada material utilizado, desta forma, a cultivar B4377 obteve o melhor desempenho analisando as variáveis AP, AIV, NR e NVP em conjunto. As cultivares que obtiveram melhor desempenho analisando as variáveis NGV, MCG e PROD em conjunto foram AS3730 e P98Y11. Altura de planta NVP e, MCG não influenciaram na melhor produtividade de grãos. Considerando a produtividade de grãos, todos os materiais avaliados podem ser recomendados para a região.

\section{Referências}

Bossolani, JW, Poloni, NM, Lazarini, E, Bettiol, JV, Fischer Filho, JA \& Negrisoli, MM. (2018). Desenvolvimento da soja RR em função de doses de glifosato e da inoculação com Bradyrhizobium. Revista Brasileira de Engenharia Agrícola e Ambiental, 22(12): 854-58.

Bonetti, LP. (1983). Cultivares e seu melhoramento genético. Soja: genética e melhoramento. Campinas: Fundação Cargill, 741-94. 
Castoldi, R, Charlo, HCDO, Vargas, PF, Braz, LT, Mendonça, JLD \& Carrão-Panizzi, MC. (2009). Desempenho de quatro genótipos de soja-hortaliça em dois anos agrícolas. Horticultura Brasileira, 27(2): 256-59.

Companhia Nacional de Abastecimento - CONAB. (2020). Levantamento da safra 2019/2020: grãos. Brasília: Conab.

Costa, ÉD. (2013). Arranjo de plantas, características agronômicas e produtividade de soja. Dissertação (Mestrado). Universidade Estadual Paulista, Faculdade de Ciências Agronômicas de Botucatu, 201p.

Cruz, CD. (2013). Genes: a software package for analysis in experimental statistics and quantitative genetics. Acta Scientiarum. Agronomy, 35(3): 271-76.

EMBRAPA, S. (2004). Tecnologias de produção de soja-Paraná-2007. Londrina: Embrapa Soja.

Francischini, JC, Borkert, CM., Ferreira, MM \& Gaudêncio, CA. (2000). Alterações na fertilidade do solo em sistemas de rotação de culturas em semeadura direta. Revista Brasileira de Ciência do Solo, 24(2): 459-67.

Leite, WDS. (2016). Seleção de genótipos de soja portadores ou não do gene RR por meio de análise multivariada e desempenho agronômico. Universidade Estadual Paulista (UNESP). Agronomia (Genética e Melhoramento de Plantas) - FCAV. 65p

Neves, JA. (2011). Desempenho agronômico de genótipos de soja sob condições de baixa latitude em Teresina-PI (Doctoral dissertation, Dissertação de Mestrado. Universidade Federal do Piauí, Teresina. 94p).

Queiroz, ED, Neumaier, N, Torres, E, Pereira, LAG, Bianchetti, A, Terazawa, F, ... \& Yamashita, J. (1981). Recomendações técnicas para a colheita mecânica. A soja no Brasil. 
Parente, TDL. (2014). Adubação nitrogenada em genótipos de soja associada à inoculação em semeadura direta no Cerrado. Revista Brasileira de Ciências Agrárias, 10(2): 249-55, Universidade Federal Rural de Pernambuco- Pernambuco, Brasil.

Pereira, AS, Shitsuka, DM, Parreira, FJ \& Shitsuka, R. (2018). Metodologia da pesquisa científica. [e-book]. Santa Maria. Ed. UAB/NTE/UFSM. Disponível em: https://repositorio.ufsm.br/bitstream/handle/1/15824/Lic_Computacao_MetodologiaPesquisa-Cientifica.pdf? sequence $=1$.

Torres, FE, Silva, ECD \& Teodoro, PE. (2014). Desempenho de genótipos de soja nas condições edafoclimáticas do ecótono Cerrado-Pantanal. Interações (Campo Grande), 15(1), 71-78.

Torres, FE, David, GV, Teodoro, PE, Ribeiro, LP, Correa, CG \& Júnior, RAL. (2015). Desempenho agronómico e dissimilaridade genética entre genótipos de soja. Revista de Ciências Agrárias, 38(1): 111-117.

\title{
Porcentagem de contribuição de cada autor no manuscrito
}

\author{
Marcos Vinícius Barros Pinto - 25\% \\ Francisco Eduardo Torres - 15\% \\ Angelita dos Santos Zanuncio - 15\% \\ Paulo Eduardo Teodoro - 15\% \\ Gabriele Gonçalves de Mendonça - 15\% \\ Denise Prevedel Capristo- $15 \%$
}

